\title{
Language of stressed people. Linguis- tic analyses of the divided self and a loss of control
}

\section{LOUISE HALLSTRØM ABILDGAARD, CHRISTINA FOGT- MANN AND CHRISTIAN GADEN JENSEN}

Stress constitutes an increasing public mental health problem and the stress concept grows increasingly complex. There is no specific defining cluster of symptoms, and stress symptoms are also applied diagnostically within several physical and mental illnesses. This challenges systematic knowledge development and consequently it varies whether a given stressful condition will be characterized as justified for treatment or not. This is highly pertinent in Denmark, where public stress clinics are being established to offer stress assessment and treatment. Studies of first person experiences of stress are mainly phenomenological, and in this paper we suggest to supplement this perspective with a linguistic approach, namely that of Systemic Functional Linguistics. We argue that this approach can provide more specified insights into the experience of stress and thereby strengthen research and treatment. We conduct systematic analysis of four citizens' linguistic expressions in eight interviews before and after the 9-week stress reduction program, Open and Calm (OC). The results reveal an expressed division of the self from the body and a loss of control. After OC, a perceptual connection to the body was strengthened and control partly restored. We discuss the practical applicability of the findings and of linguistic analysis in future stress research and practice. 